\title{
2013 SA Heart Congress report
}

\section{6th World Congress of Paediatric Cardiology and Cardiac Surgery and \\ 14th Annual Congress of the South African Heart Association}
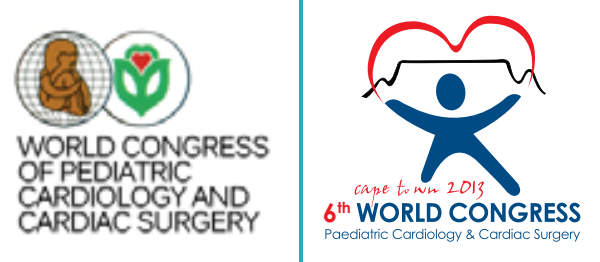

The 6th World Congress of Paediatric Cardiology and Cardiac Surgery held in Cape Town in February was hosted by the South African Heart Association and organised by the Paediatric Cardiac Society of South Africa. This was the most important event in cardiac care to have ever been held in Africa. The word "success" is too vague and we prefer to say that, together with our faculty of over 366, we achieved something significant: a forum in which ideas were shared and which provoked thinking, where old friendships were renewed and new friendships were made and where new things were learnt and innovative ideas explored. All with one common goal in mind: improving the health of children with heart disease. To this end it was a satisfyingly successful week. SA Heart was a significant part of this achievement and the organising committee is grateful for the support it has received from our association.

The conference was attended by 3033 delegates of whom 2359 were medical professionals. The number of delegates attending was three times more than any other heart congress ever to have taken place on our soil and a third of the delegates were from Africa. The data conceals many lessons and rewards and the point of this report is to share those thoughts with you.

\section{OUR VISION}

We went to great lengths in our programme to balance the highest levels of achievements in research and technological development and treatment for complex lesions with the sort of health systems questions relevant to the distribution of cardiac care to needy children. In the less well-resourced countries few children with heart disease get the treatment they require. In part we had a "socio-political" agenda to reinforce the notion that these children ought not to be denied the benefits of medical science. We believe we fulfilled our vision - namely to highlight the challenges for paediatric cardiac care in less well-resourced countries and to engage government and civil society in finding solutions to the many systems deficiencies that lead to the neglect of children with heart disease. The South African government has for the first time taken notice of the neglect of children's heart disease and that is one domestic objective partially achieved.

\section{ORGANISATIONAL PARTICIPATION AND SUPPORT}

We believe the "World Congress" is the Olympics within our profession and consequently an event that should enjoy widespread and generous support. It only happens every four years so we expected that "competing" meetings would suspend their events for 2013. In a now famous and magnanimous gesture, The Children's Hospital of Philadelphia and All Children's Hospital in St Petersburg decided not to have their "Heart Week" meetings in February 2013. The World Society for Paediatric and Congenital Heart Surgery moved their 4th Congress and Scientific Meeting from 2013 to 2014. AfricaPCR, an initiative of the South African Heart Association, incorporated their meeting in the World Congress.

We chose a coherent, single, integrated programme rather than a Congress which is made up of the sum of several component parts. The international steering committee strongly supported this principle. Whilst not initially universally popular, 
we are pleased that with only one exception (PICS), all invited organisations participated enthusiastically in the World Congress. The two existing international societies (World Society for Paediatric and Congenital Heart Surgery and the International Society for Nomenclature in Paediatric and Congenital Heart Disease) both had sessions in the programme.

The morning and evening breakfast and dinner symposia did not form part of the CME programme but were very well supported. Many of them were oversubscribed in terms of people wishing to attend and several companies and institutions wanted to host a symposium only to find that all slots had been taken. The Paediatric Cardiac Intensive Care Society, AEPC, Japanese Society of Paediatric Cardiology and Cardiac Surgery, Pan Arab Congenital Heart Disease Association all had scientific symposia. Hospitals which held symposia all hailed from the USA.

In our view the important role played by parent and patient support and advocacy groups should be recognised and we are pleased that they enjoyed the international exposure afforded them. Likewise international and national humanitarian programmes were widely represented and several sessions were devoted to different models of service provision and systems development.

The special interest groups (SIGS) of SA Heart were all invited to participate in the programme. The Cardiac Arrhythmia Society (CASSA), Paediatric Cardiac Society (PCCSA), Cardiac Imaging Society (CISSA), Society of Cardiovascular Intervention (SASCl), Heart Failure Society (HeFSSA) and the Society for Cardiovascular Research (SASCAR) accepted this invitation and supported the scientific committee. SASCAR and SASCI also ran their own breakfast symposia.

\section{PROGRAMME HIGHLIGHTS}

John Lawrenson (Cardiologist) and John Hewitson (Cardiothoracic Surgeon) chaired the international scientific committee with much skill, insight and dedication.
There were 6 "tracks" which delegates could follow:

- Surgery, anesthesia and intensive care,

- Interventional cardiology,

- Health systems and heart disease,

- Adults with congenital heart disease and preventing adult heart disease,

Nursing science and

- Cardiology and imaging.

The culture of paediatric cardiac care is one in which we "work together." This is possibly true for children's cardiac care more than for any other area of tertiary health care. The cohort of people from junior to senior, across specialities, across nursing-physician "barriers" and together with the NGOs, are all identifiable by this common feature - that in every way possible, we work together. This was a message we tried to convey in the design of the programme. We believe in this respect another objective was fulfilled. All of the sessions in every track were open to every delegate.

The surgical track plumbed the depths of left ventricular outflow tract obstruction with all manner of associated anomalies. This focus on a single lesion (as was the case with "atrioventricular septal defect" in Cairns four years ago), proved popular. Acquired heart disease in general and rheumatic heart disease in particular were given a strong platform. RHD ran in one of the II parallel venues for the entire week featuring in the surgical, cardiology, imaging and health systems sections of the programme. These sessions were very well supported, complimenting congenital disease (which dominated the programme) recognising the fact that over 30 million people are affected by RHD worldwide and in most of the world children with RHD represent half of the burden of heart disease. 
Supported by a team from our intervention partner "CSI", led by Shakeel Qureshi and Neil Wilson, the intervention programme ran live cases on 3 of the 5 days. Whilst transmission on Monday the 18th from Europe (Frankfurt and Milano) was by satellite, live transmission from within South Africa was streamed via broadband internet. There was scepticism about the choice of this modality but it proved as reliable as satellite transmission with good quality images at a much reduced cost. Two of our strongest supporters, the hospital groups Netcare and MEDICLINIC, enjoyed excellent exposure from Christiaan Barnard Memorial, Sunninghill and Panorama hospitals. The live case programme brought forth many "firsts" in Africa, including transcather pulmonary and tricuspid valve implantations and a wonderful showcase for what can be done on our continent. The intervention programme was not an appendage to but a full and vital track within the World Congress programme.

The nursing science track was well attended with enthusiastic participation from a genuinely global audience. The ACHD track, amongst other subjects, interrogated the challenges of care for Fontan and Tetralogy of Fallot patients and also women in their reproductive years. The number of delegates in these sessions fell short of our expectations but this was possibly the consequence of other competing and compelling attractions. On the other hand, "AfricaPCR" held on Friday as part of Track 4 proved very successful and popular amongst our adult cardiology and surgical colleagues. There was a forum for case presentations and the highlights were learning how to perform TAVI and mitral valvuloplasty.

We have had very supportive feedback on the novel "Lecture of your life" talks which provided content outside our "box". The highlights of the programme were without question the 20 plenaries and in particular the lectures that honoured Jane Somerville, Donald Ross and the late Christiaan Barnard.

\section{ABSTRACTS}

In the call for papers (managed with considerable passion and commitment by Liesl Zühlke) | 405 abstracts were submitted, | 273 were accepted and 977 were finally shown at the Congress ( 123 orally and 854 as E-posters). The loss of circa 300 papers can be attributed to a variety of reasons but there were many more people wanting to present their abstract orally than we were able to accommodate. If we had another chance, we would cut the number of "lecture" sessions from the parallel tracks and double up on the oral abstracts.

E-posters were shown in the well attended "Abstract café". Although there was some scepticism before the congress, we received only compliments about this technologically modern format. We feel our decision to go with digital presentations was vindicated and that the future for abstracts and posters is unequivocally in the digital domain. The Abstract café was a great success.

Abstracts were published in two journals, namely the SA Heart Journal and the Cardiovascular Journal of Africa and can be viewed, along with all the slide presentations, at www.wcpccs20 I3.co.za.

\section{INDUSTRY AND EXHIBITION}

We managed to attract a large industry exhibition with 74 companies exhibiting at 124 booths or stands and we are extremely grateful to all our generous supporters whose names and logos are to be found at www.wcpccs20I3.co.za. Sonja du Plessis, from Londocor, well known to all of us at SA Heart, was responsible for the organisation of the industry and exhibition. As usual she did this with considerable style and professionalism and the scale of our achievement is a measure of her enormous contribution.

We found that neither the growing burden of "adults with congenital heart disease" nor the inclusion in the programme of preventative cardiology or lifestyle disease, constructed a compelling case with the pharmaceutical industry well known for their pessimism regarding the benefits (to them) of supporting "paediatric cardiology". There were glaring absences from global pharmaceutical companies who enjoy a strong footprint on African soil. The extraordinary 5 day structural heart disease intervention programme and "AfricaPCR" facilitated solid support from the device industry. Medtronic was by far the most generous industry supporter of the Congress and their role is gratefully acknowledged. Plated lunches and all tea breaks were served in the large exhibition hall which attracted large numbers of delegates into the exhibition and proved a popular move amongst industry. 


\section{THE ENVIRONMENT}

The carbon footprint of international conferences is appalling. It is very costly to try to offset the environmental impact of intercontinental air travel with the purchase of "carbon "credits" but through the use of recycled materials (for the delegate bags), the avoidance of bottled water and keeping printed material to a minimum, we trust we made a positive contribution.

\section{FINANCIAL CONSIDERATIONS AND FEES}

The budget was considerable. Invited faculty are the costliest investment followed, in our case, by the rent of the Convention Centre. One third of the budget was generated by grant support and donations which were secured years before the congress from Netcare, MEDICLINIC, PepsiCo, the Department of Health and the National Lottery Distribution Trust Fund. Without this backing and security, we would not have gone ahead with the event. The industry exhibition and sponsorships generated 15\% and the balance was generated by delegate fees. A loan of R500 000 was provided in yearly instalments over a 5 year period, by SA Heart. The Paediatric Cardiac Society provided a loan of R700 000.

Despite the parlous state of the global economy, we managed to keep our delegate fees below that of the previous World Congress. Although not financially viable, the very cheap "super early bird" registration brought in over 300 paying delegates 10 months before the Congress and those delegates served as a registration vanguard for other people from their institutions.

The reduced rates offered to less well-resourced countries is an imperative and we followed the precedent set at the 5 th World Congress with the World Banks "low income country" definition being the criteria. This low income discounted category was expanded to include delegates from all African countries, including South Africa. We believe it would be more appropriate to have low and low middle income countries and suggest this for the 7th World Congress in 2017.

\section{LEGACY PROJECTS}

The most important legacies of a World Congress must surely be the outflow resulting from the meeting of minds and sharing of new ideas and information. These outcomes develop slowly, out of reach and beyond awareness, often without any measure or acknowledgment.

It was also important for us that a project of this magnitude leaves a tangible legacy in our country. Thus far we have supported the following projects:

- Multi-lingual children's heart disease information system (with Scientific Software Solutions),

- KidzPositive (NGO for children with AIDS) and

- 9 homes and institutions for orphaned and needy children have benefited from the left over blankets (I 000) and congress bags.

We will be supporting the introduction of newborn oximetry programme in South Africa.

\section{CONCLUSION}

The 6th World Congress has been a major undertaking and certainly the biggest and most important event with which we will ever be associated. We submitted our bid in 2007 and this congress has consumed the lives of many of us on the organising committee, especially for the past 2 years. It has been a defining time in our lives, both a burden and a pleasure, but looking back it was in every way worth it, the struggles are forgotten and the delight lives on! We extend our congratulations and thanks to everyone involved in any way.

\section{Christopher Hugo-Hamman \\ Chairman}

